\title{
A historia magistra vitae e o pós-modernismo
}

\section{The historia magistra vitae and Postmodernism}

\author{
Juliana Bastos Marques \\ leirunirio@gmail.com \\ Professora adjunta \\ Universidade Federal do Estado do Rio de Janeiro \\ Av. Pasteur, 296 - Urca \\ 22290-240 - Rio de Janeiro - RJ \\ Brasil
}

\section{Resumo}

Pretendo neste artigo fazer uma proposta de crítica às abordagens mais recentes da Teoria da História, mormente de Reinhard Koselleck e Jörn Rüsen, mas também dos pós-modernos, que identificam uma ruptura radical entre modelos de historiografia da Antiguidade clássica e da modernidade. Partindo das reflexões preliminares de Arnaldo Momigliano sobre a questão, proponho identificar tanto as abordagens dos autores citados quanto as dos pós-modernistas como parte de um Zeitgeist que desconsiderou algumas premissas antigas da relação entre história, utilidade, verdade e exemplo, oferecendo uma ressignificação de tais relações nos tempos atuais.

\section{Palavras-chave}

Historia magistra vitae; Pós-modernismo; Historiografia antiga.

\begin{abstract}
This paper proposes a critique of some current views in Theory of History, mainly by Reinhart Koselleck and Jörn Rüsen, but also by the Post-Moderns, who identify a radical break between historiographical models of classical antiquity and modernity. Starting from the preliminary analysis of Arnaldo Momigliano on the issue, I propose to identify the different approaches of these modern authors as part of a Zeitgeist that has discarded some ancient assumptions of the relationship between history, truth, utility and example, offering a reframe of such relationships for our contemporary times.
\end{abstract}

\section{Keywords}

Historia magistra vitae; Postmodernism; Ancient historiography. 
Gostaria de convidar o leitor a acompanhar um raciocínio em construção. ${ }^{1}$ As reflexões que pretendo apresentar aqui são o fruto de questionamentos advindos de duas circunstâncias diferentes, mas que ocorreram em momentos próximos entre si. Ministrei recentemente um curso de Teoria da História na pós-graduação da Unirio e tive assim a grata oportunidade de retomar o contato com diversos textos fundamentais sobre a história da historiografia e os modelos teóricos que já há tempos eu havia esquadrinhado, mas que depois deixei de lado, em meio ao trabalho e às pesquisas pontuais da especialização que a carreira muitas vezes nos impõe. Porém, antes mesmo do curso eu já havia me deparado com uma provocação que muito me incomodou - no bom sentido. Jörn Rüsen esteve na Unirio em 2010, apresentando em uma palestra seu modelo teórico em formato de círculo, que denomina matriz disciplinar da historiografia (RÜSEN 2009; 2011). Aberta a sessão para as perguntas, inquiri a respeito da relação dos estudiosos atuais com a historiografia antiga, haja vista que muitas das categorias da divisão dessa matriz disciplinar me remetiam a pressupostos da escrita da história tal como a historiografia antiga os delimita. De fato, caro leitor, esclareço de antemão que minha especialidade não é a historiografia contemporânea, mas sim a antiga. O que me moveu a inquirir Rüsen e seus pares, como farei adiante, era tão somente a constatação, para mim muito intrigante, de como os mundos de ambas as especialidades dialogam tão pouco entre si.

Embora o círculo da matriz disciplinar de Rüsen não seja estritamente hermenêutico (MEGILL 1994, p. 52), há nele sinais bastante claros dos padrões clássicos quanto à relação entre a escrita e a compreensão do texto. A resposta seca e objetiva do palestrante à minha pergunta me deixou perplexa: "a historiografia antiga hoje é inútil, pois a ruptura moderna é total e irreversível". Minha reação de discordância, embora contida, foi - admito - instintiva. No entanto, a provocação funcionou como um excelente motor de questionamento. Procurei a partir de então me colocar a pergunta: por que a historiografia antiga ainda seria, sim, relevante como referência para a historiografia contemporânea? Os argumentos que apresento a seguir são a minha resposta.

\section{Rüsen, Koselleck e os pós-modernos, ou o que Momigliano gostaria de saber}

Acredito que, na verdade, a resposta de Rüsen provavelmente se referia mais à autonomia científica do discurso histórico na modernidade do que às questões que me preocupavam - assim, em última instância, sua resposta partiria de uma proposição do tipo, "a historiografia antiga é inútil simplesmente porque não é a nossa". No entanto, a ideia da ruptura entre esses dois mundos de especialização ainda é parte de uma abordagem recorrente nos teóricos atuais da historiografia. Outro nome que advoga a mesma posição é o de Reinhart Koselleck, por sinal antecessor de Rüsen na cadeira de Teoria da História na Universidade de Bielefeld. No capítulo intitulado "Historia magistra vitae - 
Sobre a dissolução do topos na história moderna em movimento" de seu livro Futuro passado, o próprio título já adianta o argumento central: o topos só era possível enquanto o mundo andava em passos lentos, com as transformações sociais ocorrendo durante um longo período de tempo - dado que havia "uma constância efetiva das premissas e pressupostos" (KOSELLECK 2006, p. 43). Porém, segundo ele, o fim do século XVIII introduziu a emergência do novo, do progresso e da revolução, assim como havia percebido Tocqueville, entre diversos outros autores oitocentistas. Pela primeira vez, a modernidade, em constante conflito de identidade perante o antigo, assumia-se como triunfante, em um superior rumo em direção ao futuro. ${ }^{2}$ Para isso, Koselleck destaca o papel da Revolução Francesa, mas há de se ressaltar em seu argumento também o triunfo da burguesia e o advento da era industrial, motores econômicos, para além do plano político, na valorização do novo.

No entanto, o principal argumento de Koselleck é relativo à própria história do conceito de história: ele aponta a substituição do termo "Historie" por "Geschichte" como ponto fulcral da distinção entre a validade da historia magistra vitae e a da concepção contemporânea (juntarei esta última com "pós-moderna" adiante, data venia) de história. Segundo Koselleck, foi por volta de 1750 que os autores alemães passaram a usar o termo "Geschichte", antes relativo apenas ao acontecimento em si (das Geschehen), para definir a história como conhecimento de si mesma - tal como formula Droysen (apud KOSELLECK 2006, p. 49). Como disciplina acadêmica autônoma, a Geschichte removia o sentido didático dos exemplos do passado nos quais a Historie se constituía - e o historicismo surge também nesse contexto para caracterizar de maneira única e inequívoca as diferentes realidades históricas, fazendo com que a história não tivesse mais uma utilidade didática exterior a si mesma, na aplicação cotidiana de pressupostos de conduta moral (KOSELLECK 2006, p. 55). Além disso, se a Historie explicava tudo e julgava a todos - como em sua última grande manifestação, as histórias conjecturais e filosóficas iluministas -, o novo sentido de Geschichte criava como consequência lógica a filosofia da história e os sistemas racionais tais como os de Herder e Kant, que propunham o novo valor didático de uma unicidade da história, em que o exemplo particular não mais teria importância.

Ouso dizer que a primeira coisa que me vem à cabeça em face dessas propostas é quão inelutavelmente local é esse conjunto de conceitos e desenvolvimentos. ${ }^{3}$ Para as línguas que continuam se utilizando do termo original "historêin" para definir o foco de seus estudos, acaba parecendo até mesmo impróprio mergulhar no universo das filosofias da história alemãs sem ter em conta essa distinção linguística que reflete também em boa medida a própria construção da identidade nacional alemã entre o fim do século XVIII e

\footnotetext{
2 É a mesma visão de François Hartog, que identifica a historiografia hoje como voltada para o presente, em contraposição às historiografias antiga e moderna. No entanto, sua concepção é inadvertidamente circunscrita a uma determinada realidade, a da crise atual europeia: "A autoridade do futuro se desintegrou, principalmente na velha Europa" (HARTOG 2011, p. 45).

${ }^{3}$ Assim como o caso do contexto local do próprio Rüsen, analisado em MEGILL 1994, p. 44 e WIKLUND 2008. Cf. SAWILLA 2011.
} 
o século XIX. É válida a morte total da historia magistra vitae fora das filosofias da história e dessa distinção tipicamente alemã? A parte explica o todo da modernidade pós-revolução?

Quem procurou responder essas perguntas foi não menos do que Arnaldo Momigliano (CHRIST 1991), em um famoso artigo de 1975. Koselleck parece algo relutante em reconhecer o problema que Momigliano aponta: "o paradoxo de que a historiografia clássica não foi desacreditada ou considerada inútil quando os propósitos da escrita da história se tornaram diferentes" (MOMIGLIANO 1979, p. 140). O formato da narrativa histórica sobre guerra e diplomacia no século XIX ainda derivava dos modelos antigos, como em Tucídides e sua metodologia precursora da história científica em Ranke. A erudição acadêmica ainda continuava solidamente plantada em raízes clássicas, pois, desde os primórdios da educação escolar até o cume da formação intelectual das elites europeias, voltada para a política (portanto, para a guerra e a diplomacia), Cícero, César e Tito Lívio continuavam incólumes como bases didáticas (SCHEIN 2008). Os modelos políticos de Esparta, Atenas e da Roma republicana serviram também como referenciais para os movimentos liberais e nacionalistas na esteira da queda de Napoleão.

Para Momigliano, o ponto de virada teria sido outro, por volta de 1860, com a valorização da história medieval como fundadora das histórias nacionais europeias, o surgimento da dialética, da história cultural e de novas disciplinas como a Sociologia e a Antropologia Social, sustentadas pela nova base das teorias evolucionistas (MOMIGLIANO 1979, p. 144-145). Sendo assim, os estudiosos do mundo antigo teriam passado a estudá-lo a partir não das próprias referências clássicas, mas sim de novas perguntas relacionadas a novas preocupações e abordagens - o que teve o interessante efeito colateral de multiplicar os estudos sobre a Antiguidade. Para Momigliano, a historiografia nunca deixaria de remeter ao mundo clássico, já que "será sempre considerada uma criação típica ou ao menos uma formalização da cultura grega, que é assim interessante para se estudar no seu próprio contexto grego" (MOMIGLIANO 1979, p. 148). Parece evidente que Momigliano não estava focado na questão da historia magistra vitae da mesma maneira que Koselleck, até porque muito de sua obra se concentra nas diferenças entre os tipos de historiografia existentes no mundo antigo (MOMIGLIANO 1990; Cf. FORNARA 1983). A esta altura, espero que o leitor já tenha percebido que, quando menciono o termo de Cícero, historia magistra vitae, estou usando uma metonímia para a - bem mais diversificada - historiografia antiga como um todo, dado que é muitas vezes com esse topos que a historiografia moderna menciona a sua equivalente antiga, pensando em especial nos humanistas do Renascimento e nos iluministas. ${ }^{4}$ De fato, há um componente de exemplaridade já em Heródoto e Tucídides (GRETHLEIN 2011), ainda que ela tenha sido mais sistematicamente utilizada apenas a partir do período helenístico, como vemos em Políbio, e se

${ }^{4}$ Até mesmo pelo fato de que uma grande parcela deles tinha maior familiaridade com a língua latina do que com a grega. 
realizado plenamente dentro do pensamento romano, com a importância do mos maiorum (ROLLER 2009). ${ }^{5}$

Neste ponto, é interessante observar como praticamente não há diálogo entre os dois mundos do estudo da historiografia antiga e da moderna: ${ }^{6}$ Koselleck não dialoga com Sir Ronald Syme, Keith Hopkins ou Rostovtzeff, para ficar apenas entre alguns autores citados por Momigliano. Este, por sua vez, malgrado sua imensa erudição, não se aventura nos campos de Droysen, Hegel ou Kant. ${ }^{7} \mathrm{O}$ artigo de George Nadel (1964), bastante conhecido entre os estudos sobre historiografia moderna e contemporânea, é praticamente ignorado pelos antiquistas, se não por Finley ${ }^{8}$ e alguma bibliografia mais recente (ROLLER 2009). Assim, o fim da historia magistra vitae não é um problema claramente delimitado por Momigliano, porque para ele é evidente que o referencial clássico permanece - aliás, vemos a importância que o autor Ihe atribui na parte final de seu texto, onde encontramos uma virulenta condenação do pós-modernismo. Ele diz:

O que é novo em nosso tempo é que existem importantes correntes de pensamento que relativizam todos os historiadores - seja os do mundo clássico ou os de outras eras - e os consideram meros exponentes de ideologias, ou mesmo mais restritamente, de centros de poder. Portanto, a historiografia fica destituída de qualquer valor na busca pela verdade. Pode-se suspeitar que os autores de tais afirmações sobre os historiadores, sendo eles próprios historiadores, abrem uma exceção secreta para eles mesmos. Mas isso seria um consolo pobre, pois a autocontradição não é uma saída. Acredito que seja a combinação do declínio na autoridade dos historiadores clássicos como guias do mundo clássico com o declínio da autoridade de qualquer historiador como transmissor potencial da verdade, que realmente caracteriza nossa situação (MOMIGLIANO 1979, p. 148).

A versão que tenho desse texto é de uma edição da Fondation Hardt que contém uma discussão com outros historiadores - também especialistas no mundo clássico - sobre os pontos levantados no artigo. Walter Burkert faz uma pergunta direta sobre as consequências dessa guinada pós-moderna que deixa Momigliano totalmente desarmado: "O que pode ser dito sobre as causas desse desenvolvimento aqui constatado, dessa perda da realidade na historiografia?" Momigliano responde: "Eu gostaria de saber. Meu artigo teria sido diferente, e nossa discussão também" (MOMIGLIANO 1979, p. 156).

O leitor especialista em historiografia contemporânea pode estar pensando a essa altura: "mas Rüsen não é pós-moderno!" Ora, Momigliano nasceu em 1908, Koselleck, em 1923, Rüsen, em 1938, e eu, em 1977. O que quero dizer com

\footnotetext{
${ }^{5} \mathrm{O}$ texto de Roller complementa meus argumentos na medida em que se contrapõe a Koselleck e Nadel para identificar também na historiografia antiga não só exemplos abundantes da operacionalização narrativa dos exempla, como também um eventual "proto-historicismo" nos historiadores antigos.

${ }^{6}$ Há de se notar uma importante e recente tendência em contrário, a partir dos estudos sobre a recepção do mundo antigo no mundo moderno. Cf. LIANERI 2011.

7 É fato que Momigliano faz uma crítica à obra Geschichte des Hellenismus, de Droysen, em artigo publicado na década de 1970. No entanto, o debate em seu texto gira em torno de questões específicas sobre a adequação do termo "helenismo" e do período helenístico, e não sobre questões de método, ainda que, como é de seu estilo, apareçam algumas considerações incidentais sobre o tema. Cf. HÜBSCHER 2010.

8 Citado como nota de rodapé em "Mito, memória e história", primeiro capítulo de Uso e Abuso da História. São Paulo: Martins Fontes, 1989, p. 3, cuja versão original foi publicada em History and Theory, Vol. 4, p. 281-382, 1965
} 
isso é que existem diferenças imensas na percepção de mundo dessas diferentes gerações. Enquanto Momigliano não entende como se pode resolver o paradoxo pós-moderno, os alemães ainda parecem menos familiares com ele do que com o seu próprio presente da modernidade em crise - ambos viveram o nazismo, a culpa do pós-guerra, a ascensão e a queda do comunismo na Alemanha. Eu - e quiçá também o leitor - já nasci em um mundo cujo sentido não pode ser mais desligado da desconstrução pós-moderna, malgrado tantas críticas a esta; cabe a nós, portanto, entender os rumos nos quais se desdobra esse problema de identidade na historiografia. Assim, as críticas de Rüsen e de Koselleck, embora não sejam evidentemente críticas pós-modernas per se, ${ }^{9}$ estão inegavelmente inseridas em um ambiente de ruptura dos paradigmas da modernidade.

Sigo, até por uma questão geracional, na esteira do que Momigliano gostaria de saber e que Koselleck e Rüsen criticaram, na negação da importância do referencial antigo da historiografia para os pós-modernos. O pós-moderno é o resultado estridente das consequências do novo na modernidade: definido a partir dos anos 1970 e consolidado definitivamente com os novos paradigmas sociais e tecnológicos do mundo da virada do milênio, ${ }^{10}$ consiste temporalmente - parto de Perry Anderson (1999) - na derrocada final do antigo mundo aristocrático, mas também no fim do triunfante mundo burguês modernista, no arranjo político "sem nuances" submetido ao capitalismo especulativo e, em especial, no triunfo do progresso aceleradíssimo da tecnologia e de seu alcance global. Os teóricos pós-modernistas, referenciados pela vivência no próprio fim do modernismo, ainda tateiam em busca de definições teóricas abrangentes que não sejam contraditórias entre si. Afinal, uma das principais críticas ao pós-modernismo é que duas das suas principais características, a fragmentação e o pastiche, acabaram levando a uma situação paradoxal em que a desconstrução dos paradigmas anteriores levou, em última instância, ao vazio (THOLFSEN 1999).

Esse problema também tem se apresentado no caso da historiografia a partir das seguintes características defendidas pelo pós-modernismo (VEUREN 1995): 1) existe uma quebra ontológica entre a história e o passado, ou seja, não se pode de maneira alguma conhecer o passado objetivamente, "wie es eigentlich gewesen ist". Assim, o estudo do passado se refere não ao próprio, mas a um circuito fechado de relatos e narrativas que tem um fim em si mesmo; 2) como um corolário da primeira, o foco primordial da história deve ser a interpretação e não o fato em si. Qualquer evidência do passado apenas faz sentido em relação à sua interpretação e não existe fora dela; sendo assim, a verdade está relacionada, não ao fato, mas sim ao discurso; 3) as interpretações são necessariamente circunstanciadas pelos contextos de quem as produz, e, portanto, não são intercambiáveis - postura que, aliás, revela de forma inequívoca o caráter historicista do pós-modernismo; 4) se não há abstração universal possível entre essas interpretações, ou esses discursos, a grande teoria não tem qualquer posição superior - aliás, sequer faz sentido. Surgem

\footnotetext{
${ }_{9}^{9}$ Dada a maior afinidade, ao menos no caso de Rüsen, com a ideia - vinda dos antigos - de que a historiografia deveria cumprir uma função orientadora na vida (RÜSEN 2007).

$10 \mathrm{Ou}$, talvez, estes anunciem a própria derrocada do pós-modernismo, inaugurando outra era - assim defendem Lipovetsky (2005) e Kirby (2009).
} 
assim as microteorias, que explicam apenas relações locais, no espaço e no tempo, reflexo último da retórica das relações de poder em uma determinada sociedade.

Um conhecido exemplo de análise da relação entre pós-modernismo e historiografia é o artigo de Frank Ankersmit, "Historiography and Postmodernism", publicado em 1989 no History and Theory, ao qual se seguiu um acalorado debate com Perez Zagorin na mesma revista, no ano seguinte. ${ }^{11}$ Não pretendo aqui esmiuçar os detalhes da discussão, nem todos os pontos propostos por Ankersmit, mas gostaria de destacar um dos principais pontos defendidos por ele. Seu texto começa com uma constatação que acredito bastante verdadeira da situação da produção acadêmica desde a década dos anos 1970, que é o aumento exponencial do número de historiadores e, portanto, de discursos sobre o passado, nas últimas décadas. Esse aumento, que espelha o aumento geral da produção de informação e conhecimento no mundo, também acaba por significar que as fontes secundárias tomam cada vez mais a primazia sobre as fontes primárias, tornando-se elas próprias fontes primárias e assim sucessivamente (ANKERSMIT 1989, p. 137). Tal como acabamos de ver sobre as características do pós-moderno quanto à primazia da interpretação, diz Ankersmit:

As interpretações históricas do passado primeiro se tornam reconhecíveis e adquirem suas identidades através do contraste com outras interpretações; elas são o que são apenas a partir do que não são. Qualquer um que conheça apenas uma interpretação, por exemplo, da Guerra Fria, não conhece absolutamente nenhuma interpretação deste fenômeno (ANKERSMIT 1989, p. 142).12

É natural, dessa forma, que Ankersmit se conecte a Hayden White e a Paul Ricoeur, especialmente ao primeiro, pela valorização da linguagem, da primazia do estilo, da forma do texto, sobre a realidade e o conteúdo da narrativa histórica.

A consequência de tudo isso é que a verdade, ou melhor, as múltiplas verdades, dado que advêm da interpretação dos discursos, estariam fora da história - do parâmetro moderno tradicional, científico, de história. Se a história não contém a objetividade nem a verdade, então seria inútil buscar essas últimas duas. A propósito, é até divertido ver como os pós-modernistas caem em contradição quando advogam tais posturas radicais: Keith Jenkins, ao mostrar argumentos de como é inútil buscar a verdade, acaba apresentando neles o que quer tomar como verdades (VEUREN 1995). E é aqui também que vemos um dos grandes problemas causados pela intuição lógica desse argumento de que não há verdade passível de observação na história, exemplificado pela famosa polêmica do revisionismo do Holocausto (SPIEGEL 2007).

Se para os pós-modernistas a história não contém a verdade e seria, portanto, inútil, temos aqui, enfim, o ápice da negação da historia magistra vitae. A teoria pós-moderna é mais radical do que a discussão de Koselleck ou mesmo de Rüsen sobre esse ponto. É fato que Koselleck nunca tratou diretamente do pós-modernismo em seus estudos, preferindo se concentrar na modernidade - 
especialmente alemã - a partir do século XVIII. Sua rejeição do termo "pós-moderno" se dá por razões semânticas, apontando o autor que o termo "moderno" abarca de maneira suficiente o novo perante o antigo, no que dizer "pós-moderno" soaria como uma tautologia (BRORSON 2004). Admito que, quanto a essa questão, o termo "pós-moderno" também me incomoda profundamente - presumo que a minha geração eventualmente precisará cortar o nó górdio. Já Rüsen também não pode ser colocado como pós-moderno - aliás, como vimos, muito pelo contrário: seu pensamento defende uma volta à análise racional da história e à definição dos princípios normativos do conhecimento histórico.

\section{Os pressupostos da historiografia antiga e o mundo (pós-)moderno}

Sendo assim, para onde vamos, se os pós-modernos nos dizem que a historiografia antiga é inútil hoje? Retomemos então os elementos básicos da historiografia antiga, para depois confrontá-los com esse problema da abordagem pós-moderna. Destacarei neles principalmente a verdade, mas também a autoridade do autor, a utilidade da obra e o estilo empregado (MARINCOLA 1997). Quanto à verdade, tratarei de sua relação com a função do exemplum na narrativa histórica, discutindo seu pressuposto lógico da imutabilidade do caráter humano. Nesse sentido, a discussão toma um rumo bastante diferente do usual entre os estudiosos, que desde a filologia clássica do século XIX têm se concentrado nas questões do método para se estabelecer a verdade pelo testemunho. Para tanto, vamos exemplificar a questão fazendo uma breve análise do proêmio de Heródoto. ${ }^{13}$ A tradução, baseada na divisão analítica de Krischer (1965), é de Tatiana Oliveira Ribeiro (2010):

1. Esta é a apódexis (exposição) da investigação de Heródoto de

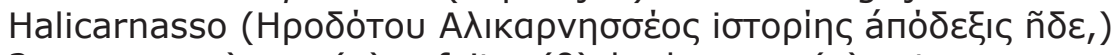

2. para que a) nem (a) os feitos $(\beta)$ dos homens $(\gamma)$ se tornem evanescentes por ação do tempo,

b) nem (a) as grandes e admiráveis obras, $(\beta)$ realizadas tanto pelos gregos quanto pelos bárbaros, ( $Y$ ) fiquem sem glória,

3. e em particular, por que motivo entraram em guerra uns com os outros.

Vejamos: se as musas inspiram Homero e são a garantia de verdade da narrativa, Heródoto logo de cara se anuncia, em terceira pessoa, como ele mesmo o autor e único responsável pelo que será apresentado, sua apódexis. A narrativa é verdadeira e legítima porque ele a pesquisou (historêin), usando todos os testemunhos possíveis que encontrou em sua busca. Do que fala Heródoto? Dos feitos dos homens. Qualquer feito? Não, os feitos grandiosos dos gregos e dos persas, e "em particular por que motivo entraram em guerra uns com os outros". Por que Heródoto expõe esses feitos? Para que não "se tornem evanescentes por ação do tempo", para que não se esqueça de sua glória (ainda um eco de Homero), ou seja, para preservar sua memória. E qual é a razão pela qual se

\footnotetext{
${ }_{13}$ Não seria incorrer em anacronismo usar Heródoto como parte da historia magistra vitae definida por Cícero, pois parto de um sentido que a define como "historiografia antiga" em oposição à "moderna". Não pretendo entrar aqui em detalhes sobre a ruptura ciceroneana com a tradição anterior do gênero historiográfico; para tanto, ver FELDHERR 2003.
} 
deve preservar a memória desses grandes feitos? A história em Heródoto tem a si mesma como objetivo, tal como o texto pós-moderno? Claro que não: o objetivo primordial de Heródoto é que a preservação da memória dos grandes feitos sirva como exemplo de conduta para o leitor. Se o termo ainda não é tão explícito como na historiografia latina, a preocupação transparece sem dúvida por todo o texto de Heródoto, seja, por exemplo, na história de Creso, no livro I, seja no fracasso anunciado pela hybris de Xerxes, no livro VII. Por sinal, o exemplo negativo pode ser tão importante como o positivo, haja vista os motivos principais da própria obra de Tucídides, ao mostrar como também a hybris dos atenienses foi responsável por sua ruína (FORDE 1986; MAGALHÃES 2012).

Podemos dizer, então, que o propósito último da historiografia e de suas variantes (a biografia, os comentários, etc.) no mundo grego e latino é ensinar pelos exemplos - positivos e negativos. Como já mencionado, é fato que a historiografia grega clássica não sistematiza tão claramente essa necessidade quanto os helenísticos e em especial os latinos posteriormente o fazem, e aqui penso na diferença entre instâncias quase incidentais de exemplos desde Homero (GRETHLEIN 2010) versus os objetivos explícitos de Políbio, Tito Lívio e Tácito, ou mesmo do não historiador Cícero e a famosa frase que compõe o título deste artigo (NADEL 1964), para mencionar apenas os principais (MOMIGLIANO 1972). Logo, a consequência lógica de tal objetivo, que definiria um pressuposto básico da reflexão histórica antiga, é que a natureza humana seria imutável - insistirei na singularidade desse ponto. Sendo assim, um exemplo muito anterior à vida e ao contexto social e político do leitor poderia ser automaticamente utilizado como guia de referência para a conduta moral e cívica, na medida em que o erro moral seria inerente à natureza humana.

Não há uma ruptura com essa ideia durante o período medieval, no que Isidoro de Sevilha, Beda (KOSELLECK 2006, p. 44) ou Gregório de Tours narram os fatos da história pagã no consciente propósito de mostrá-los como exemplo, ainda que isso oferecesse um risco incidental de privilegiar os modelos do mundo pagão em detrimento dos modelos cristãos. ${ }^{14} \mathrm{Não}$ há também ruptura nos modelos renascentistas de Leonardo Bruni (IANZITI 1998) e Maquiavel, ainda que ambos ressaltem as especificidades da história das cidades italianas. Não há ruptura nas histórias conjecturais do século XVII e começo do século XVIII, que procuraram interpretar as sociedades avançadas do Novo Mundo pelos modelos políticos greco-romanos (CAÑIZARES-ESGUERRA 2001). Voltaire, no verbete Histoire da Encyclopédie, já descarta muito do fantástico de Heródoto ou de Gregório de Tours, diferenciando com maior rigor a crítica interna da crítica externa, e já distingue importantes diferenças na natureza do mundo moderno em relação ao mundo antigo. No entanto, ainda ele insiste na utilidade da história para aprender com os acertos e erros do passado, com base implícita em premissas morais. ${ }^{15}$

\footnotetext{
14 "O quanto se permanecia cristão ao se remeter a Tito Lívio, Tácito ou Tucídides como guias era algo em aberto. Na prática, o que mais impressionou o observador externo foi a propensão dos historiadores, e dos eruditos em geral, a preferir assuntos não cristãos a cristãos" (MOMIGLIANO 1979, p. 135).

${ }^{15}$ A discussão de Voltaire no artigo é eminentemente metodológica. No entanto, são frequentes as alusões a um senso comum de valoração moral nas épocas do passado: "Com o desmembramento do Império Romano no Ocidente, começa uma nova ordem das coisas, que é chamada de Idade Média - história bárbara dos povos bárbaros, que se tornaram cristãos, mas não se tornaram melhores" (VOLTAIRE 1765, p. 223).
} 
De fato, continuaremos por todo o século XIX, mesmo dentro da tal ruptura anunciada por Koselleck, encontrando diversos autores que ainda farão paralelos diretos com elementos do mundo antigo. Só será o distinto e único século $X X$, que presencia coisas nunca antes vistas no mundo, como a guerra total e a bomba atômica, que verá o abandono total do referencial clássico.

Se a existência do exemplo na narrativa histórica está naturalmente ligada à sua aplicabilidade, é possível deduzir, como seu corolário, a presença implícita ou direta da questão da (i)mutabilidade do caráter humano, aspecto que dialoga profundamente com a filosofia. Assim, a ruptura apontada acima desenvolve um caráter específico no mundo da razão iluminista, em que Kant e Hegel defendem a mutabilidade do caráter humano ao longo da história, como demonstram seus modelos racionais de explicação. Para Kant, na Ideia de uma história universal sob o ponto de vista cosmopolita, o caráter humano seria mutável, porque é historicamente mudado, dado que se constitui na percepção humana da razão na sua natureza e na realização dessa razão pela autoconsciência e minimização do antagonismo entre o caráter sociável e o egoísta do homem, no plano pessoal, e entre as nações, no plano da sociedade civil. Esse antagonismo implícito na "sociabilidade insociável dos homens"16 tenderia a zero, mas não poderia se realizar totalmente, pois, se acabasse, isso seria uma contradição em termos com o sentido oculto da natureza no homem, dado que "os atos humanos, bem como qualquer outro fenômeno da natureza, são determinados por leis naturais de caráter universal". ${ }^{17}$

Podemos dizer que também para Hegel o caráter humano seria mutável, na medida em que a sua historicidade é a consciência humana progressiva da liberdade do Espírito. E é interessante notar que, nas últimas páginas da Filosofia da história, Hegel aponta, diferentemente de Kant, para o fim da realização da razão na história, localizando a Reforma protestante na Alemanha como o ponto chave. Condenando o catolicismo francês e sua incompatibilidade com a busca da liberdade depois da Revolução Francesa, para Hegel é na Alemanha protestante que se conciliam definitivamente a liberdade, o direito e a religião. Eis que chega a consciência humana à sua realização, e assim conclui Hegel: "A história universal é o processo desse desenvolvimento e do devir real do espírito no palco mutável de seus acontecimentos - eis aí a verdadeira teodiceia, a justificação de Deus na história". ${ }^{18}$

Dessa forma, eu gostaria de propor que talvez a questão da (i)mutabilidade da natureza humana seja uma chave para entendermos as diferenças entre a historiografia antiga e os modelos modernos que a ela se seguiram. Porém, aqui precisaríamos enveredar para o campo filosófico, o que carrega um problema, já que o conhecimento histórico tem um eminente caráter empírico, o historêin, e o conhecimento filosófico é por natureza abstrato. E não é necessário ir tão longe para nossos propósitos aqui; se confrontarmos os pressupostos antigos da

\footnotetext{
16 4a. Proposição: "die ungesellige Geselligkeit der Menschen".

17 GARDINER 1974, p. 28. No original, "die menschlichen Handlungen, eben so wohl als jede andere Naturbegebenheit nach allgemeinen Naturgesetzen bestimmt".

18 Tradução da edição brasileira de 1995. No original,"Daß die Weltgeschichte dieser Entwicklungsgang und das wirkliche Werden des Geistes ist, unter dem wechselnden Schauspiele ihrer Geschichten, - dies ist die wahrhafte Theodicee, die Rechtfertigung Gottes in der Geschichte".
} 
historiografia que levantamos agora com a filosofia da história de Kant e Hegel, eles ainda assim continuam pertinentes: a verdade não mais está no fato, mas subsiste enquanto validade e pertinência da razão, ou do Espírito. Assim, conclui-se que há e deve haver para esses filósofos um relato verdadeiro: aquele de como a razão/Espírito se manifesta ou se revela na história. Um exemplo disso está no que acabei de dizer sobre Hegel em relação à Reforma, que ele aponta ser o momento em que a consciência de si em Deus se torna finalmente pessoal - daí ser a Bíblia luterana, para Hegel, o livro nacional alemão.

Um segundo elemento constituidor da historiografia antiga é a autoridade, que, se para os antigos é vinculada à posição social do autor e a seu domínio da tradição que o precede (MARQUES 2008), já em Kant estaria na capacidade de conhecer, dominar e apresentar os mecanismos da progressão humana na história em direção à realização da razão na natureza do homem. Sendo assim, sua utilidade estaria exatamente na explicação e exemplificação desse processo. Dessa forma, tanto a história tradicional, magistra vitae, quanto as filosofias da história se apresentam como lógica e necessariamente verdadeiras, dado que escritas por uma autoridade autorreconhecida (e posteriormente também reconhecida nas respectivas tradições em que se encaixa), e que, pelo próprio caráter da verdade, mostram-se como úteis - tanto ao revelar a imutabilidade do caráter humano quanto para o entendimento em contrário.

A questão do estilo, que vem a complementar os pressupostos fundamentais da historiografia antiga, pode também ser analisada porque nos remete precisamente de volta ao debate de Hayden White e Ankersmit. Em poucas instâncias da história da historiografia o estilo deixou de ser importante e, por longo tempo, seguiu os preceitos da retórica clássica (RICOEUR 1994; LAIRD 2009), a inventio, a dispositio e a elocutio (descartando aqui os ligados à apresentação oral, memoria e pronuntiatio). A inventio em particular está relacionada à verdade na medida em que se subordina à investigação e/ou ao relato dos testemunhos, mas também se liga à verossimilhança. Há inúmeros exemplos na historiografia antiga que eu poderia citar para exemplificar essa questão, como nas diferentes versões que Tito Lívio apresenta, em especial na primeira década, ou como nos rumores palacianos típicos de Tácito, mas citarei novamente Heródoto, com a anedota do faraó Psamético, que ordenou a um pastor que criasse dois bebês em completo isolamento e sem que ouvissem qualquer palavra para que, quando crescessem e falassem pela primeira vez, essa primeira palavra revelasse se os egípcios ou os frígios seriam os povos mais antigos: "Que isso foi o que realmente aconteceu, foi o que eu mesmo aprendi com os sacerdotes de Hefesto em Mênfis, embora os gregos tenham várias versões improváveis da história, tal como a que Psamético ordenara que as crianças fossem criadas por mulheres cujas línguas haviam sido cortadas. Porém, a versão dos sacerdotes é essa que eu apresentei" (II, 1, 3). ${ }^{19}$

Os autores renascentistas ainda seguem essas regras à risca, e também as histórias conjecturais e filosóficas do século XVIII usam o artifício da verossimilhança

$\overline{19}$ A passagem é bastante analisada. Cf. GROTEN 1963; SULEK 1989; LATEINER 1989. 
como determinador da verdade nos seus relatos. As estritas regras filológicas da história científica já mudam o quadro, mas, mesmo assim, os autores ainda se preocupam com a questão do estilo - como mostra o próprio Hayden White quando analisa, por exemplo, os casos de Michelet, Ranke, Burckhardt e Tocqueville (WHITE 2008). Nesse sentido, surpreende que os pós-modernistas alcem o estilo à proeminência atribuindo a ele certo caráter de ineditismo. ${ }^{20}$

Ankersmit propõe que o estilo prevalece sobre o conteúdo, quando afirma:

[...] graças ao fato dos pontos de vista historiográficos serem incomensuráveis - isto é, que a natureza das diferenças de opinião em história não pode ser satisfatoriamente definida em termos de objetos de estudo - nada podemos fazer além de concentrarmo-nos no estilo incorporado a cada ponto de vista histórico ou olhar sobre o passado, se quisermos garantir um progresso significativo do debate na História. O estilo, se não o conteúdo, é o tema de tais debates. O conteúdo é derivado do estilo (ANKERSMIT 1989, p. 144).

Evidentemente, não podemos fazer um paralelo absoluto com o mundo antigo, mas proponho um exercício que nos fará chegar mais perto de Heródoto. Trocando os termos "ponto de vista histórico" por "testemunho", teríamos:

graças ao fato dos testemunhos serem incomensuráveis - isto é, que a natureza das diferenças de opinião quanto aos fatos não pode ser satisfatoriamente definida em termos de objetos de estudo - nada podemos fazer além de concentrarmo-nos no estilo incorporado a cada testemunho, se quisermos garantir um progresso significativo do debate na História.

Em outras palavras, dada a dificuldade de se estabelecer a verdade por causa dos diferentes testemunhos, a inventio e todas as demais regras que delimitam a história enquanto gênero literário se tornam as ferramentas fundamentais para a escrita da história no mundo antigo.

\section{Conclusão}

O breve e subversivo laboratório de comparação acima tem um propósito específico definido: apontar que, em certo sentido, não podemos afirmar uma ruptura completa e total entre os pressupostos da historiografia antiga e as tateantes características da historiografia pós-moderna. E isso acontece por causa de um motivo elementar: romper completamente com a definição de um objeto significa negá-lo; no caso que nos ocupa, isso significa que a escrita da história deixa de fazer sentido. A história é sempre discurso porque é recorte, e isso se aplica ao discurso/recorte pós-moderno ou ao antigo, independentemente das outras características que os diferenciam. Esse recorte nunca é arbitrário: ele tem determinados objetivos, é deliberado e consciente. Assim, se a história, por definição, contém alguma verdade - ou melhor, não é deliberadamente ficcional -, é necessariamente útil na medida em que responde a determinados anseios

${ }^{20}$ Ankersmit, mas não Hayden White. 
e à vida do leitor, identificando-se ou não este com uma narrativa induzida. ${ }^{21}$ Advogo, portanto, que nem no mundo do historicismo pós-modernista é possível uma exclusão total da ideia de exemplo, ${ }^{22}$ pois seu aspecto de utilidade é condição lógica da verdade que compõe a escrita da história. Permita-me, caro leitor, ousar tal definição, já que aqui estou pensando na diferença entre "a" história e "uma" história, ou seja, "um" discurso. Além disso, tenho plena consciência de que podem existir utilidades não ligadas estritamente aos exemplos de conduta moral - enfim, acredito, na verdade, que Rüsen e eu não discordaríamos tanto. Portanto, para o próximo passo, é crucial perguntar: útil para quem? Os exemplos da historia magistra vitae tradicional eram claramente direcionados para uma pequena parte da sociedade: a elite aristocrática, os grandes políticos e generais. ${ }^{23}$ Porém, o alargamento do campo de pesquisa do historiador que se dá a partir do século XIX, com a interdisciplinaridade e especialmente após o estouro dos estudos culturais pós-modernos e pós-coloniais, expandiu de maneira exponencial o sentido de "exemplo". Também nessa possibilidade de alargamento de sentido, "exemplo" não significa apenas conduta moral, mas qualquer referencial que possa, de maneira direta ou indireta, fazer com que tenhamos consciência de nosso próprio mundo - uma urgência tão pós-moderna e, ao mesmo tempo, tão perene.

\section{Referências bibliográficas}

ANDERSON, Perry. As origens da pós-modernidade. Rio de Janeiro: Zahar, 1999.

ANKERSMIT, Frank. R. Historiography and Postmodernism. History and Theory, Vol. 28, no 2, p. 137-153, 1989.

BRORSON, Kristine. Koselleck and postmodernism. Oslo, 2004. Disponível em: http://www.historiologicalnotes.org/2004/03/koselleck_and_p.html. Acesso em: 13 de abril de 2013.

BURKE, Peter. Exemplarity and anti-exemplarity in early modern Europe. In: LIANERI, Alexandra. (ed.) The Western Time of Ancient History. Historiographical Encounters with the Greek and Roman Pasts. Cambridge: Cambridge University Press, 2011, p. 48-59.

CAÑIZARES-ESGUERRA, Jorge. How to Write the History of the New World: Histories, Epistemologies, and Identities in the Eighteenth-Century Atlantic World. Stanford: Stanford University Press, 2001.

CHRIST, Karl. Arnaldo Momigliano and the History of Historiography. History and Theory, Vol. 30, no 4, p. 5-12, 1991.

\footnotetext{
${ }^{21}$ Roller (2009, p. 216) sintetiza, por outro caminho, em termos precisos: "[...] there can plainly be no "pure" historicism in which a past is known to the present exclusively on its own terms, without any imposition of present frameworks or concerns. For no historian can avoid posing and answering questions from within her or his own horizons of possibility and value, which ex hypothesi differ from those of the past in question. Nor, probably, has 'pure' exemplarity ever been attained. Even before the advent of historicism as an articulated philosophy of history, certain changes over time, or differences between past and present, could always be perceived".

22 É curioso notar, como adendo à questão, a permanência mesmo hoje do topos ciceroneano na percepção da utilidade da história fora do círculo de especialistas acadêmicos. Cf. BURKE 2011.

${ }^{23}$ E suas virtuosas esposas; ver a popularidade de Plutarco até o século XVIII.
} 
FELDHERR, Andrew. Cicero and the invention of "literary" history. In: EIGLER, Ulrich (ed.). Formen römischer Geschichtsschreibung von den Anfängen bis Livius: Gattungen, Autoren, Kontexte. Wiss: Buchges, 2003, p. 196-212.

FORDE, Steven. Thucydides on the Causes of Athenian Imperialism. The American Political Science Review, Vol. 80, no 2, p. 433-448, jun. 1986.

FORNARA, Charles W. The Nature of History in Ancient Greece and Rome. Berkeley: University of California Press, 1983.

GRETHLEIN, Jonas. The Greeks and their past: poetry, oratory and history in the fifth century BCE. Cambridge: Cambridge University Press, 2010.

. Historia magistra vitae in Herodotus and Thucydides? The exemplar use of the past and ancient and modern temporalities. In: LIANERI, Alexandra. (ed.) The Western Time of Ancient History: Historiographical Encounters with the Greek and Roman Pasts. Cambridge: Cambridge University Press, 2011. p. 247-263.

GROTEN, Jr., F. J. Herodotus' Use of Variant Versions. Phoenix, Vol. 17, no 2, p. 79-87, Summer 1963.

HARTOG, François. Time's authority. In: LIANERI, Alexandra. (ed.) The Western Time of Ancient History: Historiographical Encounters with the Greek and Roman Pasts. Cambridge: Cambridge University Press, 2011. p. 3347.

HEGEL, Georg W. F. Filosofia da História. 2a edição. Brasília: Editora UnB, 1995. Disponível em: http://gutenberg.spiegel.de/buch/1657/1. Acesso em: 13 de abril de 2013.

HÜBSCHER, Bruno. Arnaldo Momigliano: história da historiografia e do mundo antigo. Dissertação (Mestrado em História Social). São Paulo: Faculdade de Filosofia, Letras e Ciências Humanas. Universidade de São Paulo. São Paulo, 2010. Disponível em: http://www.teses.usp.br/teses/ disponiveis/8/8138/tde-12112010-164136/. Acesso em: 31 de maio de 2013.

IANZITI, Gary. Bruni on writing history. Renaissance Quarterly, Vol. 51, n० 2, p. 367-391, 1998.

KANT, Immanuel. Ideia de uma História Universal de um Ponto de Vista Cosmopolita. In: GARDINER, Patrick. Teorias da História. 2a. edição. Lisboa: Calouste Gulbenkian, 1974, p. 28-41. Disponível em: http:// www.korpora.org/Kant/aa08/015.html. Acesso em: 13 de abril de 2013.

KIRBY, Alan. Digimodernism: How new technologies dismantle the postmodern and reconfigure our culture. London: Continuum, 2009.

KOSELLECK, Reinhart. Futuro Passado: contribuição à semântica dos tempos históricos. Rio de Janeiro: Contraponto/Editora PUC-Rio, 2006. 
KRISCHER, Tilman. Herodots Prooimion. Hermes, Vol. 93, p. 159-167, 1965.

LAIRD, Andrew. The rhetoric of Roman historiography. In: FELDHERR, Andrew (ed.). The Cambridge Companion to the Roman Historians. Cambridge: Cambridge University Press, 2009. p. 197-213.

LATEINER, Donald. The Historical Method of Herodotus. Toronto: University of Toronto Press, 1989.

LIANERI, Alexandra. (ed.) The Western Time of Ancient History: Historiographical Encounters with the Greek and Roman Pasts. Cambridge: Cambridge University Press, 2011.

LIPOVETSKY, Gilles; CHARLES, Sébastien. Hypermodern times. Cambridge: Polity, 2005.

MAGALHÃES, Luiz Otávio de. Tucídides (460 a.C.-404 a.C.). In: PARADA, Maurício (org.). Os Historiadores: Clássicos da História. Rio de Janeiro/ Petrópolis: PUC-Rio/Vozes, 2012, p. 32-50.

MARINCOLA, John. Authority and Tradition in Ancient Historiography. Cambridge: Cambridge University Press, 1997.

MARQUES, Juliana Bastos. Mecanismos de legitimidade e tradição na historiografia latina. Goiânia: História Revista (UFG), Vol. 13, p. 139-156, 2008.

MEGILL, Allan. Jorn Rusen's Theory of Historiography between Modernism and Rhetoric of Inquiry. History and Theory, Vol. 33, no 1, p. 39-60, 1994.

MOMIGLIANO, Arnaldo. Tradition and the classical historian. History and Theory, Vol. 11, no 3, p. 279-293, 1972.

. The place of ancient historiography in modern historiography. In: den BOER, W. (ed.) Les Études Classiques aux XIXe. et XXe. siècles : leur place dans I'histoire des idées. Genève: Vandoeuvres/Fondation Hardt, p. 1979. (Entretiens sur I'Antiquité Classique, tome XXVI)

. The Classical Foundations of Modern Historiography. Berkeley: University of California Press, 1990.

NADEL, George H. Philosophy of history before historicism. History and Theory, Vol. 3, no 3, p. 291-315, 1964.

RIBEIRO, Tatiana O. A apódexis herodotiana: um modo de dizer o passado. 2010. 206 f. Tese (Doutorado em Letras Clássicas). Faculdade de Letras. Universidade Federal do Rio de Janeiro. Rio de Janeiro, 2010.

RICOEUR, Paul. History and Rhetoric. Diogenes, Vol. 42, no 168, p. 7-24, December 1994.

ROLLER, Matthew. The Exemplary Past in Roman Historiography and Culture. In: FELDHERR, Andrew (ed.) The Cambridge Companion to Roman Historians. Cambridge: Cambridge University Press, 2009, p. 214-230.

RÜSEN, Jörn. Razão Histórica. Brasília: Editora UnB, 2001. 
. Como dar sentido ao passado: questões relevantes de meta-história. História da historiografia, Vol. 2, 2009. Disponível em: http://www. ichs.ufop.br/rhh/index.php/revista/article/view/12. Acesso em: 13 de abril de 2013.

SAWILLA, Jan Marco. On Histories, Revolutions, and the Masses. In: JUNGE, Kay; POSTOUTENKO, Kirill (eds.). Asymmetrical Concepts After Reinhart Koselleck: Historical Semantics and Beyond. Bielefeld: Transcript Verlag, Vol. 20, 2011. p. 165-196.

SCHEIN, Seth L. 'Our Debt to Greece and Rome': Canon, Class and Ideology. In: HARDWICK, Lorna; STRAY, Christopher. (eds.). A Companion to Classical Receptions. Malden, Mass./Oxford: Blackwell, 2008, p. 75-85.

SPIEGEL, Gabrielle M. Revising the Past Revisiting the Present - How Change Happens in Historiography. History and Theory, Theme Issue 46, p. 1-19, 2007.

SULEK, Antoni. The Experiment of Psammetichus: Fact, Fiction, and Model to Follow. Journal of the History of Ideas, Vol. 50, no 4, p. 645-651, Oct. - Dec., 1989

THOLFSEN, Trygve R. Postmodern Theory of History: A Critique. Memoria y civilización: anuario de historia de la Universidad de Navarra. no 2, p. 203-222, 1999. Disponível em: http://dspace.unav.es/dspace/ bitstream/10171/8985/1/MC_2_09.pdf. Acesso em: 13 de abril de 2013.

VEUREN, Pieter van. Does it Make Sense to Teach History Through Thinking Skills? Inquiry: Critical Thinking Across the Disciplines, Vol. 14, no 3, p. 72-81, 1995.

VOLTAIRE. Histoire. In: DIDEROT, Denis; D'ALEMBERT, Jean. Encyclopédie, Ou Dictionnaire raisonné des sciences, des arts et des métiers. Paris, 1765. p. 220-224. Vol. 8. Disponível em: http://fr.wikisource.org/wiki/ L'Encyclopédie/Volume_8\#HISTOIRE. Acesso em: 13 de abril de 2013.

WHITE, Hayden. Meta-História: a imaginação histórica do século XIX. São Paulo: Edusp, 2008.

WIKLUND, Martin. Além da racionalidade instrumental: sentido histórico e racionalidade na teoria da história de Jörn Rüsen. História da Historiografia, no 1, p. 19-44, 2008. Disponível em: http://www.ichs. ufop.br/rhh/index.php/revista/article/view/24. Acesso em: 13 de abril de 2013.

ZAGORIN, Perez. Historiography and Postmodernism: Reconsiderations. History and Theory, Vol. 29, p. 263-274, 1990. 